\title{
Using of Nudge Approaches for Sustainable Energy
}

\author{
Taekyoung Lim* \\ Korea Research Institute for Local Administration, South Korea
}

Submission: August 24, 2020; Published: September 15, 2020

*Corresponding author: Taekyoung Lim, Korea Research Institute for Local Administration, 319, Segye-ro21, City of Wonju, Gangwon Province, South Korea

\begin{abstract}
Many politicians, program administrators, and program implementers relay more on development or diffusion of greater energy efficiency to achieve reducing energy consumption based on technological approaches. In additions, policy makers advocate price-based approaches such as taxes in order to reduce environmental pollution that causes climate change. Relatively the aspects corresponding with the energy consumption behavior change have less attention in energy efficiency policies even though problems such as moral hazards, imperfect information, and negative externalities are involved in individual behavior tendencies. The purpose of this review was to compare and contrast theories that might be used to inform public policies in energy efficiency field so as to help change people's behaviors. This review suggests that government policy needs a new approach on how successful interventions are in changing people's behavior and what policy design should be developed. This research concludes that consumer choices and consumer behavior can have major impacts on achieving sustainable use of energy toward sustainable development. Because the application of the behavioral economic approach will affect the efficiency of energy policies. This research emphasize that the behavioral economic approach could be an important starting point for policymaking.
\end{abstract}

Keywords: Nudge; Behavioral economics; Sustainable energy; Energy policies

\section{Introduction}

Energy efficiency is central to energy security. Energy efficiency can contribute to the mitigation of greenhouse gas emissions as well as helping poor households save on energy bills. Despite decades of efforts to increase energy efficiency with the diffusion of energy efficient technologies, results are still no satisfactory. Recent research on energy efficiency has shown that behavior factors of individuals may provide explanations for the failure of energy efficiency policies. They have tried to find the connection between an individual's behavior factors and energy efficiency then they have focused strongly about behavior factors to discover a solution regarding the barriers to energy efficiency diffusion for energy policy redesign.

\section{Decision-Making in Neoclassical Economic}

\section{Traditional assumption of energy policy}

Policies must often make reference to social goals in some form [1]. A traditional assumption of government policy design is rational choice theory under certain conditions. Rational choice theory generally views consumer choice as a logical process undertaken to maximize utility. In other words, an individual's observation and choices are sufficient to understand how their utility is maximized. Government policies based upon the rational choice model assume an individual behavior that if an individual's utility was not maximized by their choices, then they would have chosen another thing. Policymakers could possess reasonable certainty over the likely reaction of individuals to their policy interventions. However, the government's information regarding individual (consumer) behavior may be applied partially in policy design. Unexpected individuals' behavior can emerge in their decision-making process. These individuals unexpected behavior can be connected to policy outcome. Obviously, the government will need to understand the individuals' behavioral tendencies exactly then consider these parts in energy policy design.

\section{Rational choice approach}

Neoclassical economists assume that individuals take rational, utility maximizing decisions after considering all 
relevant information. From a rational choice theory perspective, a "rational" individual means simply one who has a consistent set of preferences over a set of alternatives [2]. "Sometimes, such preferences are simply explained as referring to the utility of the alternatives. In this concept, an alternative which will bring use greater utility will be ranked above or preferred than alternative which provides us less utility [2]". In other words, some alternatives give us "more" or "less" utility than another; the economic notion of "cost" and "benefits" then can be expressed in terms of utility. A "cost" is a loss of utility while a "benefit" is a gain in utility. Therefore, a "rational" individual is one who wants to minimize his or her costs and maximize benefits. A rational individual wants to maximize between benefits and costs [2]. Furthermore, the rational choice approach assumes the economic behavior of an individual can be considered under conditions of certainty of the optimal choice. Previous scholar assumed consumers were rational actor promoting their individual self-interest using perfect information about the costs and benefits that would follow from their actions [3]. Rational choice theory has led to numerous contributions to a positive approach. In addition, the rational choice theory assumes that optimal decision making. The optimal choice process is one of making choices to maximize utility. An optimal decision assumes that best decision is one where no alternative decision can lead to a better outcome. This rational choice theory can be a foundational presumption that explaining individual behavior [4]. However, recent analysis and studies have concentrated on the findings of research which investigates the factors which can affect consumer choice. Although the rational choice theory or optimal choice can be usefully applied to form of economic predictions situation, applying these approaches in the policy for predicting or controlling an individual's or a consumer's choice or behavior may have some limitations because consumers are subject to a range of psychological biases and use various heuristics when they making choices.

\section{Behavioral Factors in Decision-Making}

Decision making in the behavioral economics approach has been aimed at empirically demonstrating deviations from rationality. Similarly, the behavioral economics approach has been aimed at relaxing these assumptions within the rational choice approach [5]. In other words, a major shortcoming of the traditional rational choice model is that they assume too much about the capabilities of the decisions making process. There are many possible reasons or choices in terms of phenomenon; realworld problems are still characterized by extreme uncertainty and complexity. Social problems always arise and only in consequence of changes in particular circumstances of time and place. This means that there is not generally applicable one best way. In other word, the government or individual could not have fully rational decision making that predicted anything within the full range of consequences [6]. Specifically, the standard of "rationality" in the decision-making process does not determine behavior [6], Individual behavior is determined by the irrational and non-rational elements that bound the area of rationality [6]. Sometime, real-world preferences can depend on context or situations and the decision maker can make their choice depend on the emotional state. Kahneman [7] said that more work is required to find out exactly how individuals behave differently in complex decision-making situations [7].

Many studies regarding behavior economics refer to limitations of the traditional economic view. Simon [6] worked on bounded rationality [6]. And Ellsberg [8] made critiques of the standard probability [8]. "Following a study of Mind and Society (1935), they distinguished between logical, illogical and nonlogical behaviors [9]". "Logical behavior is rational choice; it is ends-ends-means reasoning where means are appropriate to goals. Illogical behavior is behavior not rooted in ends-means thinking; Pareto thought little human behavior was illogical. Non-logical thought involved sentiment and emotion, which could interfere with logical thinking [9]". In this regard, the understanding of concepts of behavioral economics that are relevant to energy efficiency could be helpful in eliminating barriers to energy efficiency. In the energy demand side, energy consumption and energy efficiency can be closely connected to illogical behaviors or non-logical behaviors of individuals. In other words, people may not choose optimally in their behavior. Unintended parts (illogical behavior or non-logical behaviors) regarding individual behavior or behavior change in energy policies can play important factors in achieving sustainable energy. Behavioral factors may provide additional explanation of why the diffusion of energy efficiency remains slow. In the perspective of the question "how behavior factors can improve energy efficiency policies," the government should consider applying the principle of behavior in energy policies. Key factors regarding behavior economics in energy efficiency can be categorized within four characteristics. It is about unintended individual characteristics which can deviate from the standard assumption of decision-making:
i. imperfect optimization,
ii. bounded self-control,
iii. nonstandard preferences, and
iv. social norm.

\section{Imperfect optimization}

The first basic deviation can be generated from standard assumption of government policies is imperfect optimization. According to Adam Smith's Wealth of Nations, individuals in the economics approach are assumed to be optimal decision makers and can make maximized interest, rational decisions based on correct calculations, as well as accurately knowing what they want [10]. However, in psychology and behavioral economics, individuals are not always good at making choices [11]. For instance, individuals can be flawed decision makers. Specifically, optimal choice generally requires considering the properties of multiple alternatives [1]. For example, the optimal choice to 
purchase a new appliance with the highest energy efficiency is to choose the best one by comparing it to all available appliances based on multiple standards such as price, energy efficiency, design, quality, and brand etc. However, individuals have a limited capacity (energy) to recognize (or compare) multiple features on all appliance, in addition to having difficulty with the complexity of process of evaluating all appliance information. In other words, individuals have limited attention and limited computational capacity. Therefore, individuals usually make a choice in a narrow way rather than a perfectly optimal choice in full range. Furthermore, the human brain appears to subjectively evaluate alternatives [1]. Although, when individuals make judgment, they assess the probabilities associated with risk, whenever individuals can make errors in judgments of probability. For example, the government has applied Minimum Energy Performance Standards (MEPS). The main objective of these policies is to mitigate some of the impacts of greenhouse gas emission. Through grant programs, the government tries to expand the installment of energy efficiency appliances. The government expects that increasing diffusion of renewable technologies or higher energy efficiency technologies will lead to reducing energy consumption. Consumers also gain long-term interest by purchasing more efficient appliances. However, consumers generally lack the information or the ability to understand and to effectively use the information in order to make optimal decision regarding energy efficient appliance and operating costs. From an individual behavior, rational choice cannot be happened even though related energy efficiency policies exist. In other words, gaps between expected energy savings and actual energy savings may be generated as another possibility by outcome of policy. Governments can logically anticipate how much energy can be saved through improved energy intensive technology by rationally using an engineering calculation approach. Energy saving based on an engineering calculation approach may overestimate energy efficiency without considering consumption behavior. In other words, the possibility that decreasing the energy price by enhancing energy efficiency technology might lead to increased energy consumption is missing by policy makers.

\section{Bounded self-control}

The governments emphasize the use of price changes through taxes and subsides [12] to change peoples' behavior. The case of carbon emissions (e.g. Pigovian taxation) can be applied as example of bounded self-control. From an economic viewpoint, the government assumes that raising the price of the carbon taxes will have an improved impact on the production of carbon emissions such as $\mathrm{CO}_{2}$. In other words, the government thinks that increasing tax cost (or prices) will lead to changing individual behavior in terms of producing pollutants. In other words, taxes are superior to energy efficiency standards because they are typically based on the neoclassical model of rational choices. However, if individuals or firms respond to taxes only as they perceive them, the optimal taxation system may be in error. Individuals' or firms' response can deviate from government intentions if they fail to attend to taxes.

In the academic field, Tsvetanov \& Segerson [12] found self-control problems exist. This research said that consumers are "tempted" by the low purchase price of the less energyefficient product, even though they do not meet energy efficiency standards [12]. Yet, consumer behavior in markets for energy use is generally thought to be far from efficient because individuals (consumers) have a tendency to pursue immediate gratification [13]. The authors point out that self-control mechanism that targets temptations such as automatic reminder messages may counter this effect.

In the classical economic model, individuals have their intention when they can accurately perceive their own interests with no difficulty. However, in reality individuals have more difficulty knowing what they want, and individuals can often be unaware of the influence of the changed tax system. These individuals' behaviors may lead to choices made in some nonstandard way. This means that government policies did not lead to change of individuals or firms behavior in response to the tax. Unintended consequences can be continued in energy policy. Absolutely, the government may assume that individuals will make the optimal decision based upon response to taxes changes. Although tax systems are a matter of considering the way in which individuals respond to taxes, people can make deviated decisions from standard assumptions, and they can show different behavior tendencies from predictable ways or policy framework if they have limited attention to tax or a lack of response to a tax. In other words, individuals can make choices that are in error; it can represent a failure of self-control [1].

\section{Multiple preferences}

The rational choice model or economic assumptions about choice include some weak assumptions about the shape and content of an individual's decision-making [1]. Individuals sometimes have subjective judgments or various preferences on their decision-making other than optimal choice. In other words, they surely could not hold pure self-interest, and many assumptions are considered as uncertain probabilities.

One reference regarding the behavior factors which affect individual choice is loss aversion. Loss aversion implies that losses loom larger in people's minds than gains [14]. Loss aversion may to some extent explain the endowment effect and the status quo bias. According to Endowment effect's definition, an individual may disproportionately value what they possess. In other words, the Endowment effect means that people have a tendency to overvalue things they already own [14]. Status quo bias is an unwillingness to change the current situation, and it tells that individuals tend to prefer "doing nothing or maintaining one's current or previous decision [15]". Loss aversion, the endowment effect, and status quo bias are likely to be relevant to 
investment in energy efficient technologies or appliances as well as to policymakers' decisions [16]. Many case studies on energy consumption behavior have explored this. For example, Levine et al. [17] found some evidence of loss aversion in Uganda [17]. This research question was what impedes efficient adoption of products? This research explained that many people do not purchase products that would appear to benefit them because of loss aversion. The authors point out that imperfect information is the main cause of loss aversion; it is also an important barrier. This article addressed that people's willingness to pay for energy efficient cook stoves increased with the introduction of payment by installments, which helped overcome constraints and the immediacy effect. For instance, Greene [18] explained the endowment effect in the energy efficiency field [18]. The performance of energy technologies about energy efficiency can be invisible (unclear) to the consumer. Even though energy-using devices are clearly labeled with energy efficiency ratings, there can be considerable uncertainty about the performance and its value can be more undervalued than their own item. Furthermore, some studies analyzed the relationship between behavioral economic principles and influences on energy efficiency diffusion, and recently, Brown university professor Steven Sloman [19] demonstrated that the non-status quo condition had a lower increase in energy consumption. This research was conducted with two groups; 67 residents who received the status quo condition, the signs that read "this light switch lives in the off position. Please keep it that way" and 96 residents who received the non-status quo condition, the signs that read "this light switch controls the light. Please turn it off [19]".

\section{Social norms}

The People may be influenced by the actions of those around them. Individual behavior is influenced by the perceived behavior of others [1]. Social and cultural norms can result in behavior expectations. According to Festingerv (1954), individuals rely on objective or non-social standards. They also compare themselves to others, especially when an objective standard is not available or is not perceived as relevant. An individual's need to belong to a social group and be accepted by it makes heeding social norms particularly important [20]. Observing what others do can strongly affect an individual's actions by influencing what they perceive to constitute appropriate behavior in a given situation. Recently, academic research emphasizes social norms. For example, Goldstein et al. [20] studied guests at a hotel in Phoenix, Arizona regarding the social norms [21]. The researchers tried several different messages: "Save the Environment," "Preserve Resources for the Future," "Partner with the Hotel to save the environment," and "Join your Fellow Citizens in Helping to Save the Environment." People reacted to the final card by reusing their towels (44.1\%). This research found that social norms can increase towel reuse by hotel guests. People responded more to social norms rather than recognition related to environmental protection conditions. Like this research, direct messages that indicate to people that most other people behave a certain way have been found to promote conformity to that behavior. In this regard, in the energy policy sector, if the government tries to show individuals how their consumption of residential energy use compared with that of their neighbors, the outcome of energy consumption saving may improve. Ultimately, the important question for public policies is whether to allow for these key behavioral deviations from the imperfect optimization, bounded self-control, nonstandard preference, and social norm. Without looking through the individual behavioral lens, the government may misunderstand the social problem, and it may disturb successful government intervention.

\section{Non-price Interventions: Nudge}

Our society needs to achieve transformation of energy systems from fossil fuels to renewable energy sources, advanced energy sources, and improved energy efficiency for sustainable energy sources toward sustainable development. How could these transitions be achieved? What kinds of government policies should be considered for sustainable energy?

These behavior insights could be used by governments and administrations to formulate policies and regulations. Recently, in the area of policy redesign, the most prominent tool for translating the findings of behavioral economics has been "nudge." As defined by Thaler and Sunstein: "A nudge is any aspect of the choice architecture that alters people's behavior in a predictable way without forbidding any options or significantly changing their economic incentive. To count as a mere nudge, the intervention must be easy and cheap to avoid. Nudges are not mandates putting the fruit at eye level counts as a nudge. Banning junk food does not." The term 'nudge' refers to an idea that was developed in recent studies in behavioral economics [22]. The 'nudge' means indirect interventions in behavioral tendencies. "Nudges are not mandating" [22]. Professor Richard Thaler [23] of the University of Chicago says that a "nudge is any small feature of the environment that attracts people's attention and alters their behavior but does so in a way that doesn't compel [23]". He also said that a "nudge is like architecture of a well-designed public space toward making better choice." Daniel Kahneman, who was awarded the Nobel Memorial Prize in economics in 2002, mentions that behavioral economics is one of the most popular ideas in public policy [24]. Behavioral economics is based on the traditional "neoclassical" model of human behavior used by economists. This essentially mathematical model says human decisions can usefully be modelled as though our choices were the outcome of solving a differential equation. Kahneman's insight is that people may not choose optimally. In other words, his key insight from behavioral economics is to incorporate such ideas with positive reinforcement without losing the mathematicality [24]. It may be able to affect an individual's motivations to change their choices and behavior effectively. Many scholars such as Daivd Laibson, a behavioral economist at Harvard University, and 
David Levne, an economist at Washington University, propose that behavioral economics' insights could be applied to public policy and services. Nudge is viewed as an intervention which alters the behavior of consumers without precluding or altering the relative prices of different choices [22].

Recently, the Department of Finance and Deregulation of the Australian Government tried to distinguish between a "pure" nudge; an "assisted" nudge, and a "shove" nudge [25]. "A pure nudge means that interventions which alter choice architecture without placing any additional" "An assisted nudge refers to an intervention which alters the choice architecture by requiring some change to current existing policy," and "A shove nudge is any policy which isn't captured by the previous two definitions, such as taxation [25]". Like this, Nudge can be used as alternative tool within a given regulatory framework or used traditional interventions.

Policy design can be a challenging process in which governments are limited by imperfect information and difficulties in predicting behavior change. However, effective application of these theories can provide improved public policy design or policy change. The role of nudges related to improved decisionmaking through the behavioral economics approach could be derived from the collaboration tool that interacts with various stockholders such as governments, local authorities, NGOs, and the private sector, because planning is clearly very complex. To succeed in sustainable development with the newly developed nudge notion, planners and public policy makers must find the appropriate channels for a diverse range of stakeholders to meaningfully participate in a wide range of related decisions. Then, they would focus on the questions of how and to what extent non-mandate or non-price interventions can be used to 'nudge' decision makers towards the sustainable use of energy. Lastly, an integrative approach would be applied to understand actual behaviors or small-scale individual's actions.

\section{Conclusion}

i. Many politicians, program administrators, and program implementers rely more on development or diffusion of greater energy efficiency technology to achieve reducing energy consumption based on technological approaches. In addition, to reduce environment pollution that causes climate change, policy makers advocate price-based approaches such as taxes. Relatively, the aspects corresponding with the energy consumption behavior change have less attention in energy efficiency policies. However, problems such as moral hazards, imperfect information, and negative externalities are involved in individual behavior tendencies. We need to rethink energy efficiency policies to get sustainable use of energy toward sustainable development. Obviously, in policy investment, pursuing energy consumption behavior change strategies is still not be considered even though behavior plays a significant role in achieving energy efficiency goals. The government needs to think about what appropriate policy should be applied. The government has to recognize that society needs the energy efficiency policies in other insights corresponding with the approach of behavior change. In order to achieve sustained growth, a combination of behavior change of energy consumption and technology's development and diffusion will be simultaneously focused on to achieve the desired outcomes. Consumer choices and consumer behavior can have major impacts on achieving sustainable use of energy toward sustainable development. The application of the behavioral economic approach will affect the efficiency of energy policies. The behavioral economic approach could be an important starting point for policymaking. The national government has to discover solutions about the question of how to effectively and efficiently influence the behavior of the individual in terms of their energy efficiency. More projects about sustainable technological development already exist (proceeding), and currently, standard approaches such as price-based incentives or subsidies to encourage optimal behavior also exist. However, these instruments will not always be effective in achieving policy objectives toward sustainable development. As the next step, society needs policies based on consumer action and the government or policymakers must understand what motivates consumers in their choices. Then, strategies related to non-price interventions that influence the consumer behavior should be generated.

\section{References}

1. Kling JR, Congdon WJ, Mullainathan S (2011) Policy and choice: public finance through the lens of behavioral economics. Brookings Institution Press, p. 247.

2. Abrams R (1980) Foundations of political analysis: An introduction to the theory of collective choice. New York: Columbia University Press.

3. Jaeger CC, Webler T, Rosa EA, Renn O (2013) Risk, uncertainty and rational action. Routledge.

4. Oppenheimer JA (2010) Rational choice theory, Encyclopedia of political theory. Publications, Thousand Oaks, CA, pp. 1150-1159.

5. Amir O, Ariely D, Cooke A, Dunning D, Epley N, et al. (2005) Psychology, behavioral economics, and public policy. Marketing Letters 16(34): 443-454.

6. Simon HA (1947) Administrative Behavior. Macmillan: London.

7. Kahnemman D, Amos T (1979) Prospect theory: An analysis of decision making under risk. Econometrica 47(2): 263-291.

8. Ellsberg D (1961) Risk, ambiguity, and the savage axioms. The Quarterly Journal of Economics 75(4): 643-669.

9. Jones BD (2003) Bounded rationality and political science: lessons from public administration and public policy. Journal of Public Administration Research and Theory 13(4): 395-412.

10. Smith A (1937) The wealth of nations [1776], p. 421.

11. Robyn A, LeBoeuf, Elder S (2005) Decision Making. Cambridge Handbook of Thinking and Reasoning. Cambridge University Press, pp. 243-265.

12. Tsvetanov T, Segerson K (2013) Re-evaluating the role of energy efficiency standards: A behavioral economics approach. Journal of Environmental Economics and Management 66(2): 347-363. 
13. Wertenbroch K (1998) Consumption self-control by rationing purchase quantities of virtue and vice. Marketing Science 17(4): 317-337.

14. Kahneman D, Knetsch JL, Thaler RH (1991) Anomalies: The endowment effect, loss aversion, and status quo bias. The Journal of Economic perspectives 5(1): 193-206.

15. Samuelson W, Zeckhauser R (1988) Status quo bias in decision making Journal of risk and uncertainty 1(1): 7-59.

16. Pollitt MG, Shaorshadze I (2011) The role of behavioral economics in energy and climate policy.

17. Levine DI, Beltramo T, Blalock G, Cotterman C (2013) What impedes efficient adoption of products? Evidence from randomized variation in sales offers for improved cook stoves in Uganda.

18. Greene D (2012) Rebound 2007: Analysis of U.S. Light-Duty Vehicle Travel Statistics. Energy Policy 41: 14-28.
19. Sloman S (2012) Energy Usage and the Status Quo Bias.

20. Baumeister RF, Leary MR (1995) The need to belong: desire for interpersonal attachments as a fundamental human motivation. Psychological bulletin 117(3): 497-529.

21. Goldstein NJ, Cialdini RB, Griskevicius V (2008) A room with a viewpoint: Using social norms to motivate environmental conservation in hotels. Journal of Consumer Research 35(3): 472-482.

22. Thaler RH, Sunstein CR (2008) Nudge: Improving decisions about health, wealth, and happiness. Yale University Press.

23. Richard HT (Interview transcript) (2009) Do you need a nudge?

24. Kahneman D (2011) Thinking, fast and slow. Macmillan.

25. Department of Finance and Deregulation (DFD) (2012) Influencing consumer behavior: improving regulatory design. Australian Government, Office of Best Practice Regulation.
Your next submission with Juniper Publishers will reach you the below assets

- Quality Editorial service

- Swift Peer Review

- Reprints availability

- E-prints Service

- Manuscript Podcast for convenient understanding

- Global attainment for your research

- Manuscript accessibility in different formats

( Pdf, E-pub, Full Text, Audio)

- Unceasing customer service

Track the below URL for one-step submission https://juniperpublishers.com/online-submission.php 